Supplement of Biogeosciences, 14, 1631-1645, 2017

http://www.biogeosciences.net/14/1631/2017/

doi:10.5194/bg-14-1631-2017-supplement

(C) Author(s) 2017. CC Attribution 3.0 License.

(c) (i)

Supplement of

\title{
Effects of low oxygen concentrations on aerobic methane oxidation in sea- sonally hypoxic coastal waters
}

Lea Steinle et al.

Correspondence to: Lea Steinle (lea.steinle@unibas.ch)

The copyright of individual parts of the supplement might differ from the CC-BY 3.0 licence. 


\section{Supplementary Tables}

\subsection{Supplementary Table S1}

Table S1. Oxygen concentrations and consumption rates during the oxygen dependency experiment and corresponding methane oxidation rates determined with ${ }^{3} \mathrm{H}-\mathrm{CH}_{4}$ in Feb. 2014. Standard deviation (n=3) of initial $\left(\left[\mathrm{O}_{2}\right]_{\text {initial }}\right)$ and final $\left(\left[\mathrm{O}_{2}\right]_{\text {final }}\right)$ oxygen concentrations, and $\mathbf{r}_{\mathrm{MOx}}$ are indicated. $t_{\text {incubation }}$ corresponds to incubation time and $\mathrm{O}_{2}$ cons. to the oxygen consumption per hour.

\begin{tabular}{lllll}
\hline $\begin{array}{l}{\left[\mathrm{O}_{2}\right]_{\text {initial }}} \\
{\left[\mu \mathrm{mol} \mathrm{L} \mathrm{L}^{-1}\right]}\end{array}$ & $\begin{array}{l}{\left[\mathrm{O}_{2}\right]_{\text {final }}} \\
{\left[\mu \mathrm{mol} \mathrm{L} \mathrm{L}^{-1}\right]}\end{array}$ & $\begin{array}{l}\mathrm{t}_{\text {incubation }} \\
{[\mathrm{h}]}\end{array}$ & $\begin{array}{l}\mathrm{O}_{2} \text { cons. } \\
{\left[\mu \mathrm{mol} \mathrm{L}^{-1} \mathrm{~h}^{-1}\right]}\end{array}$ & $\begin{array}{l}\mathrm{r}_{\text {MOx }} \\
{\left[\mathrm{nmol} \mathrm{L}^{-1} \mathrm{CH}_{4} \mathrm{~d}^{-1}\right]}\end{array}$ \\
\hline $0.02 \pm 0.04$ & $0.01 \pm 0.01$ & 8.15 & 0.001 & $1.8 \pm 0.1$ \\
$0.10 \pm 0.01$ & $0.04 \pm 0.02$ & 8.25 & 0.007 & $1.5 \pm 0.2$ \\
$0.19 \pm 0.02$ & $0.08 \pm 0.01$ & 11.70 & 0.010 & $1.4 \pm 0.2$ \\
$0.40 \pm 0.01$ & $0.08 \pm 0.02$ & 12.00 & 0.026 & $1.3 \pm 0.1$ \\
$1.8 \pm 0.0$ & $0.78 \pm 0.18$ & 12.75 & 0.082 & $1.4 \pm 0.1$ \\
$13.0 \pm 1.8$ & $7.8 \pm 1.1$ & 13.00 & 0.402 & $1.4 \pm 0.3$ \\
$39.7 \pm 1.1$ & $30.9 \pm 2.8$ & 19.85 & 0.442 & $1.5 \pm 0.1$ \\
$125 \pm 1$ & $107 \pm 0$ & 19.90 & 0.864 & $1.5 \pm 0.1$ \\
$226 \pm 1$ & $209 \pm 6$ & 19.95 & 0.815 & $1.0 \pm 0.1$ \\
\hline
\end{tabular}

\subsection{Supplementary Table S2}

Table S2. Oxygen concentrations and consumption rates during the oxygen dependency experiment and corresponding methane oxidation rates determined with ${ }^{3} \mathrm{H}-\mathrm{CH}_{4}$ in June 2014. Standard deviation $(\mathrm{n}=3)$ of initial $\left(\left[\mathrm{O}_{2}\right]_{\text {initial }}\right)$ and final $\left(\left[\mathrm{O}_{2}\right]_{\text {final }}\right)$ oxygen concentrations, and $\mathbf{r}_{\mathrm{MOx}}$ are indicated. $t_{\text {incubation }}$ corresponds to incubation time and $\mathrm{O}_{2}$ cons. to the oxygen consumption per hour.

\begin{tabular}{lllll}
\hline $\begin{array}{l}{\left[\mathrm{O}_{2}\right]_{\text {initial }}} \\
{\left[\mu \mathrm{mol} \mathrm{L} \mathrm{L}^{-1}\right]}\end{array}$ & $\begin{array}{l}{\left[\mathrm{O}_{2}\right]_{\text {final }}} \\
{\left[\mu \mathrm{mol} \mathrm{L} \mathrm{L}^{-1}\right]}\end{array}$ & $\begin{array}{l}\mathrm{t}_{\text {incubation }} \\
{[\mathrm{h}]}\end{array}$ & $\begin{array}{l}\mathrm{O}_{2} \text { cons. } \\
{\left[\mu \mathrm{mol} \mathrm{L}^{-1} \mathrm{~h}^{-1}\right]}\end{array}$ & $\begin{array}{l}\mathrm{r}_{\text {MOx }} \\
{\left[\mathrm{nmol} \mathrm{L}^{-1} \mathrm{CH}_{4} \mathrm{~d}^{-1}\right]}\end{array}$ \\
\hline $0.35 \pm 0.16$ & $0.51 \pm 1.11$ & 10.92 & -0.015 & $2.0 \pm 0.8$ \\
$0.94 \pm 0.05$ & $0.74 \pm 0.90$ & 10.92 & 0.019 & $1.1 \pm 0.6$ \\
$1.9 \pm 0.0$ & $1.3 \pm 1.1$ & 11.50 & 0.052 & $0.3 \pm 0.1$ \\
$5.2 \pm 0.2$ & $1.4 \pm 2.0$ & 11.75 & 0.322 & $0.2 \pm 0.0$ \\
$14.5 \pm 0.7$ & $8.8 \pm 0.8$ & 11.75 & 0.489 & $0.4 \pm 0.0$ \\
$55.6 \pm 3.6$ & $53.0 \pm 6.1$ & 16.75 & 0.151 & $0.3 \pm 0.3$ \\
$75.9 \pm 5.7$ & $82.2 \pm 2.4$ & 16.75 & -0.377 & $0.6 \pm 0.3$ \\
$228 \pm 2.3$ & $225 \pm 2.4$ & 16.75 & 0.215 & $0.3 \pm 0.3$ \\
\hline
\end{tabular}




\section{Supplementary Figures}

\subsection{Supplementary Figure S1}

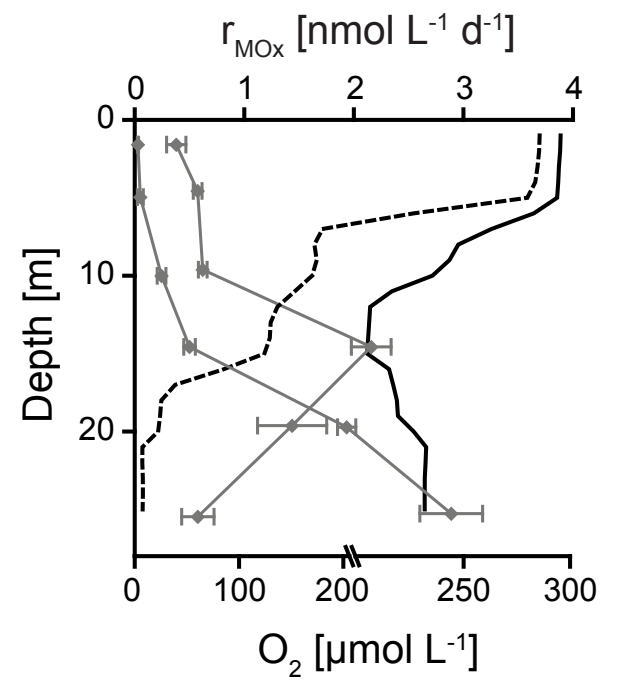

Figure S1. Profiles of unusual oxygen and methane oxidation rate profiles in Nov. 2013. Oxygen profiles (black lines) and methane oxidation rates (grey lines) from Oct. 2012 (dashed lines) and Nov. 2013 (solid lines). Error bars show the standard deviation $(n=4)$. The profiles from Oct. 2012 show a 'usual' trend for fall (i.e., depletion of oxygen with depth and increase of methane oxidation rates), whereas in Nov. 2013 profiles show some deviations (i.e., higher oxygen in bottom waters than at 10 mbsl and lower rates in bottom waters). 
(a)
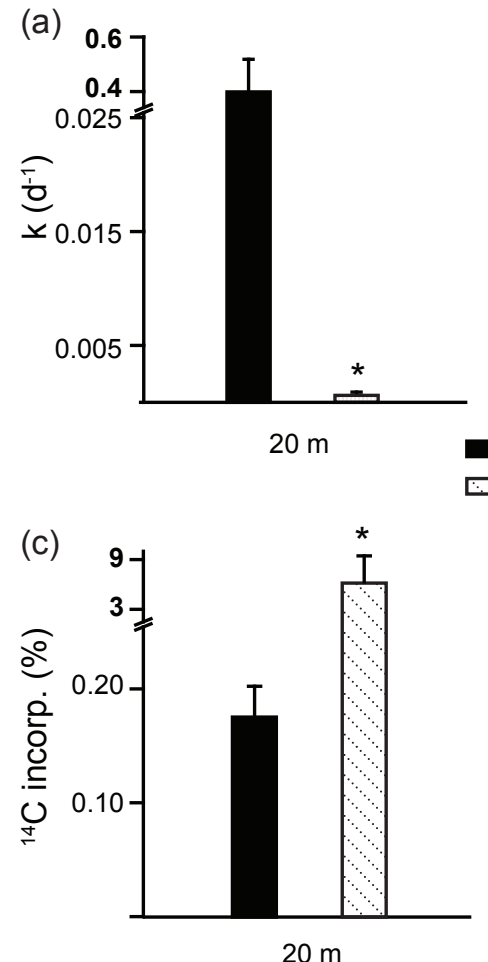

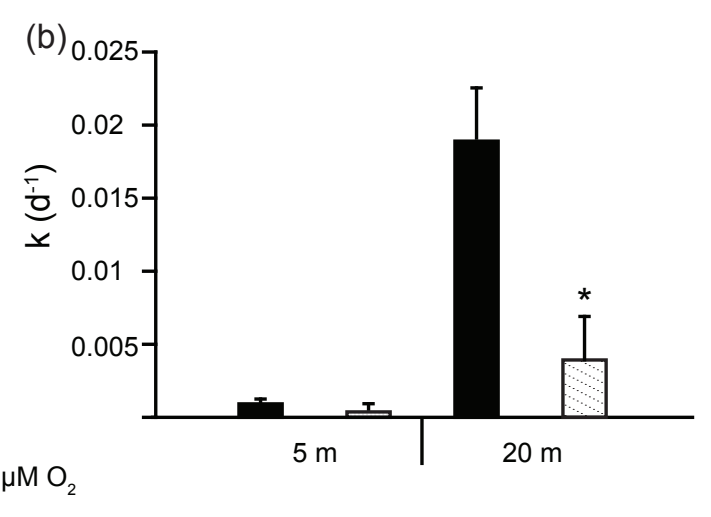

(d)

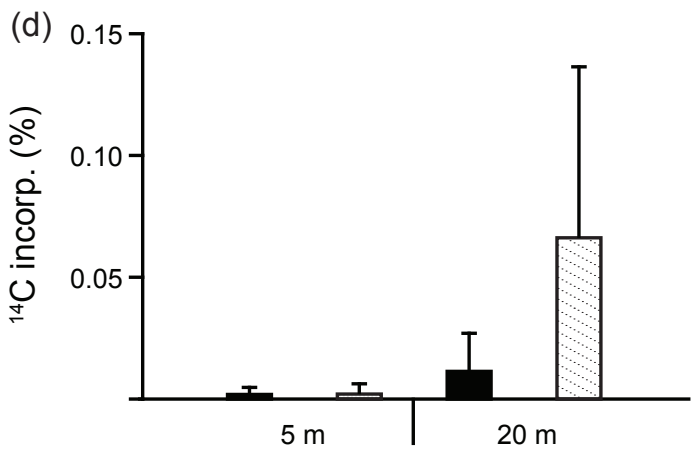

Figure S2. Methane-carbon assimilation in relation to oxygen concentration. Methane-carbon assimilation was determined from incubations amended with ${ }^{14} \mathrm{C}-\mathrm{CH}_{4}$ at saturated $\left(220 \mu \mathrm{mol} \mathrm{L}{ }^{-1}\right.$, shaded bars) or low oxygen concentrations $\left(<0.5 \mu \mathrm{mol} \mathrm{L}^{-1}\right.$, black bars) of water recovered in Nov. 2013 at $20 \mathrm{mbsl}$ (a, c) and in Feb. 2014 at 5 and 20 mbsl (b, d). Incubations were performed in triplicates and standard deviations are indicated. (a, b) First-order rate constant $k$. (c, d) Fraction of oxidized methane incorporated into biomass. Asterisks indicate a $\mathbf{p}$-value $<\mathbf{0 . 0 5}$ of a two-tailed, two-sample t-test assuming equal variance between the samples at low and high oxygen concentrations. 
(a)

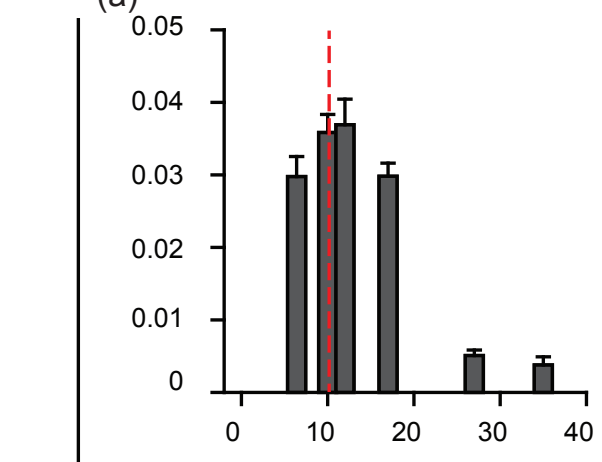

(c)

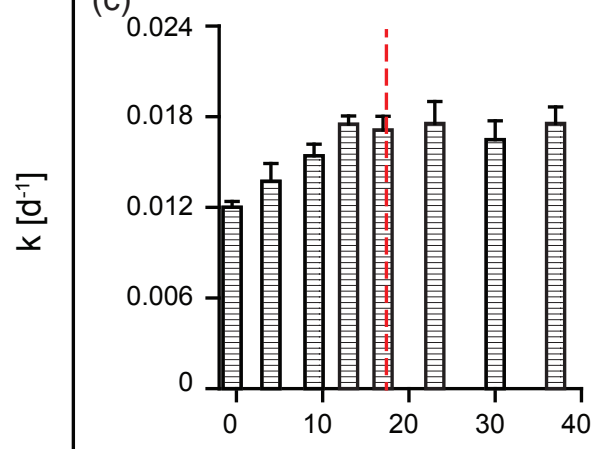

(e)

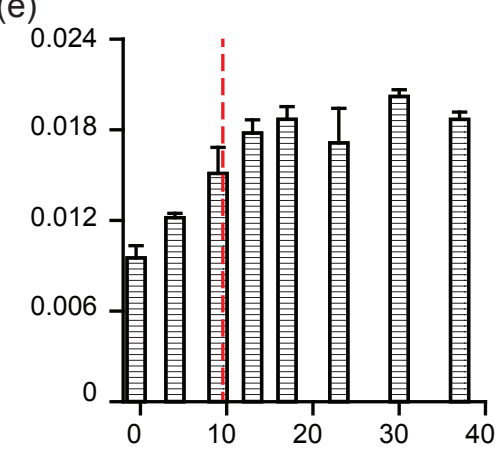

(b)

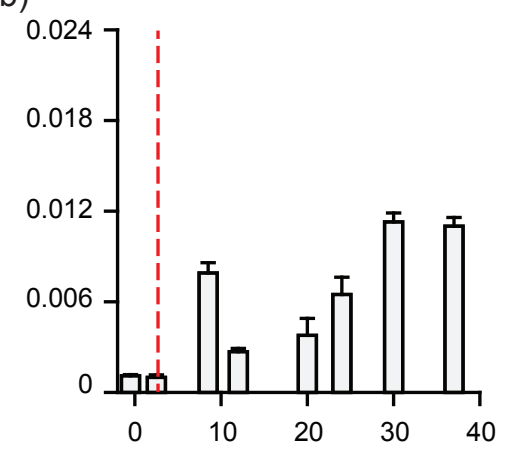

(d)

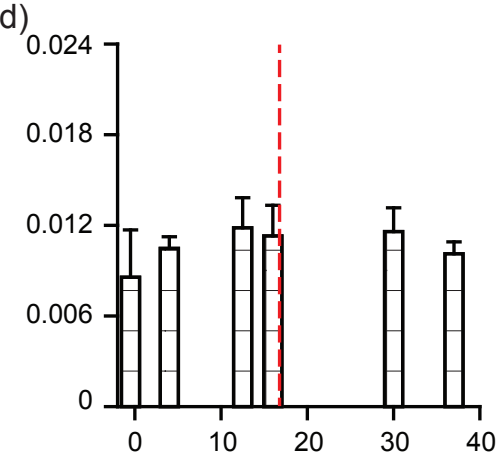

(f)

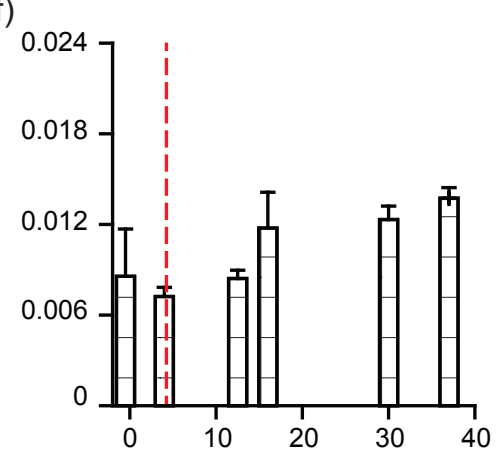

temperature $\left[{ }^{\circ} \mathrm{C}\right]$

Figure S3. MOx first order rate constants $(k)$ at different temperatures. First order rate constants of MOx were determined with ${ }^{3} \mathrm{H}-\mathrm{CH}_{4}$ amendments in triplicated incubations of water from $5 \mathrm{mbsl}(\mathrm{a}-\mathrm{d})$ and 20 mbsl (e, f), recovered in Nov. 2013 (a), Feb. 2014 (b), June 2014 (c, e), and Sept. 2014 (d, f). Red, dashed lines indicate the in situ temperatures for each date. 